\title{
A intermitência (e golpes) da (na) disciplina de Sociologia na educação escolar básica como sintoma de proposta da nova política educacional brasileira.
}

The intermittence (and coups) of the (in) Sociology discipline in basic school education as a symptom of the proposal of the new brazilian educational policy.

Alexandre De Castro ${ }^{1}$

\section{Resumo}

Ao abordarmos historicamente a presença da Sociologia como disciplina regular no ensino brasileiro percebe-se que a partir da publicação da Lei $\mathrm{n}^{\circ} 13.415$, de 16 de fevereiro de 2017, representou novo ataque e cerceamento de sua presença nos currículos, até mesmo a possibilidade da Sociologia deixar de ser ministrada no Ensino Médio brasileiro. Mas, a partir da análise de sua intermitência como disciplina no currículo escolar percebemos que o que está em jogo é uma proposta maior. Numa revisão bibliográfica no sentido de aprofundarmos nossa argumentação ficou claro que a reforma do Ensino Médio em marcha hoje no Brasil faz parte de um projeto educacional que não limita seus objetivos a um currículo destinado a promover competências e conhecimentos essenciais. Seus verdadeiros objetivos estão direcionados ao ensino como um todo, no sentido de atender políticas educacionais voltadas ao interesse econômico em detrimento de uma educação pública de qualidade e emancipadora, projeto este colocado em marcha no contexto do programa neoliberal mundial que tem seu início nos anos 1980. Confirma nossa argumentação a aquisição de

\footnotetext{
${ }^{1}$ Alexandre de Castro é doutorando em Ciências Sociais na Universidade Estadual Paulista Júlio de Mesquita Filho - UNESP Câmpus de Marília/SP onde graduou-se em Ciências Sociais Bacharelado (1995), período em que exerceu a função de Monitor junto ao Departamento de Ciência Política (1993), é Bacharel em Direito pelo Centro Universitário Eurípedes de Marília - UNIVEM (2002), Mestre em Teoria do Direito e do Estado pelo Centro Universitário Eurípedes de Marília - UNIVEM (2005).
}

Interfaces da Educ., Paranaíba, v.10, n.28, p. 29 à 46, 2019

ISSN 2177-7691

Recebido em Agosto de 2018/ Aprovado em Outubro de 2018 
vários institutos educacionais pela empresa conhecida como Kroton, realizando negócios de bilhões de reais na transação no âmbito da educação superior e básica.

Palavras-chave: Política Educacional. Sociologia. Ensino.

Neoliberalismo.

\section{Abstract}

To broach historically the presence of Sociology as a regular discipline in Brazilian education perceives that since the publication of Law 13,415 of February 16, 2017, a new attack and curtailment of its presence in the curricula, even the possibility of Sociology stop being taught in the Brazilian High School. But from the analysis of its intermittency as a discipline in the school curriculum we realize that what is at stake is a bigger proposal. In a bibliographical review to deepen our argumentation it became clear that the reform of High School in Brazil today is part of an educational project that does not limit its objectives to a curriculum designed to promote essential skills and knowledge. Its true objectives are directed to teaching as a whole, in order to meet educational policies focused on economic interest, to the detriment of a quality and emancipatory public education, a project that is set in motion in the context of the world neoliberal program that began in the 1980s. Our argument is confirmed by the acquisition of several educational institutes by the company known as Kroton, conducting business of billions of reais in the transaction in the scope of higher and basic education.

Keywords: Educational politics. Sociology. Teaching. Neoliberalism.

\section{Introdução}

Hegel observa em uma de suas obras que todos os fatos e personagens de grande importância na história do mundo ocorrem, por assim dizer, duas vezes. E esqueceu-se de acrescentar: a primeira vez 
como tragédia, a segunda como farsa. (MARX, 1978, p. 329).

Nossa epígrafe, mencionada a partir do 18 Brumário de Luís Bonaparte (1978), onde Marx relembra Hegel, para então analisar o golpe de estado perpetrado por Luís Bonaparte anos depois do Bonaparte mais famoso ter transformado a França num Império, também por intermédio de um golpe, ou seja, Luis é a farsa, da qual seu tio havia sido a tragédia, serve muito bem como comparação ao que aconteceu e tem acontecido com o ensino da Sociologia entre nós.

Sem exageros, pois a comparação é feita a partir de um olhar das Ciências Sociais no sentido da desnaturalização dos fenômenos sociais, fenômenos muitas vezes tomados como necessários, triviais e até mesmo naturais, o ensino da Sociologia na educação básica brasileira acaba de sofrer mais um golpe.

$\mathrm{Na}$ trilha da intermitência da disciplina de Sociologia com referência em Silva; Santos (2010) destacamos três fases distintas desta luta: a primeira pela institucionalização como disciplina obrigatória; seguido de um retrocesso com sua retirada dos currículos quando perde seu caráter de disciplina obrigatória e novamente sua reinserção como disciplina no Ensino Médio brasileiro.

É nesta terceira fase que percebemos, por intermédio da publicação da Lei 13.415, de 16 de fevereiro de 2017, onde estão contidos os objetivos da Base Nacional Comum Curricular que, não só a Sociologia, bem como a educação brasileira é alvo de uma nova política educacional com propósitos mercantis em detrimento de uma educação emancipadora.

A preocupação primeira, em analisar o papel da disciplina de Sociologia neste novo contexto de reformas, acabou por demonstrar que está em marcha uma política educacional com conotação bem mais ampla ao invés de simples mudança de currículos ou cargas horárias. 


\section{A intermitência da disciplina de Sociologia na Educação Escolar básica brasileira}

Mas antes mesmo de iniciarmos nossa argumentação se faz necessário historicamente relembrarmos os vários golpes sofridos pelo ensino da Sociologia no Brasil. Embora discorreremos a respeito da intermitência do ensino da disciplina de Sociologia no ensino médio, defenderemos a ideia de que o golpe agora é mais abrangente e se dá contra e Educação como um todo, do qual a Sociologia é parte.

Silva; Santos (2010) estabelecem três fases nas quais podemos entender esta trajetória da Sociologia no interior das reformas educacionais no Brasil. Uma primeira etapa, periodo delimitado entre os anos de 1891 a 1941, os autores descrevem como a Sociologia inicia sua institucionalização no Ensino Médio. A primeira proposta neste sentido se dá com a Reforma Benjamin Constant em 1891, porém retirada logo em seguida pela Reforma Epitácio Pessoa.

Primeiro golpe?

No entanto, na ebulição politica que marcou o Brasil, e em particular a cidade de São Paulo nos primeiros anos do século XX, é criada, em 1933 por influentes figuras da capital, a Escola Livre de Sociologia e Política na cidade de São Paulo na tentativa de formar quadros competentes para ingressar na administração pública, além de recuperar o espaço político perdido pelos paulistanos nas Revoluções de 1930 e 1932. Outro marco importante para a Sociologia foi a criação da Universidade de São Paulo em 1933 quando Fernando de Azevedo se torna o primeiro catedrático de Sociologia na recém-criada Universidade. O período da institucionalização da Sociologia termina com a retirada da obrigatoriedade dos cursos secundários, em 1942, pela Reforma Capanema.

Já na segunda etapa elaborada por Silva; Santos (2010) tratam da ausência da Sociologia como disciplina obrigatória durante quarenta anos (1942-1982). Apesar da defesa do retorno da Sociologia aos currículos da escola secundária em 1949 por Antonio Cândido, o 
Conselho Federal de Educação sequer listou a Sociologia como disciplina optativa em 1962. Sem esquecermos de que desde dezembro de 1961 já tínhamos nossa primeira Lei de Diretrizes e Bases. Nova reforma do ensino empreendida em plena ditadura militar, conhecida como Reforma Jarbas Passarinho, a Sociologia deixa de constar nos cursos normal.

A terceira etapa aborda a luta pela "reinserção gradativa da Sociologia no Ensino Médio" (1982-2001). A primeira vitória neste sentido se deu com a possibilidade da Sociologia como disciplina optativa pela Lei número 7.044, de 18 de outubro de 1982. No ano seguinte, já no clima da "redemocratização brasileira", a Associação dos Sociólogos de São Paulo realizam uma manifestação em prol da Sociologia e seus efeitos já se fazem sentir em 1984, com a reinserção da Sociologia nos currículos escolares do Estado paulista. Nos anos seguintes vários outros Estados passam a inserir em seus currículos o ensino da Sociologia como é o caso do Pará e Distrito Federal (1986), Pernambuco, Rio Grande do Sul e Rio de Janeiro (1989).

Marco importante para a Sociologia foi o ano de 1996 que, com a aprovação da nova Lei de Diretrizes e Bases, em 20 de dezembro, não só a Sociologia, bem como a Filosofia se tornam disciplinas fundamentais para o exercício da cidadania. Assim, em 1997, o governo federal lança os Parâmetros Curriculares Nacionais (PCNs) para orientar a reelaboração curricular, trazendo as competências específicas de Sociologia, Antropologia e Ciência Politica, orientando a renovação das diretrizes curriculares.

Mas a luta pela obrigatoriedade do ensino da Sociologia sofre nova perda. Ironia do destino da Sociologia/Ciências Sociais, a derrota veio pelas mãos de um sociólogo, então presidente da República, Fernando Henrique Cardoso (que exerceu a função por dois mandatos: 1995-2002) ao vetar projeto do Deputado do Estado do Paraná, Padre Roque, que pretendia em sua proposta tornar obrigatório o ensino de Sociologia nas escolas. Mas com a eleição de Luis Inácio Lula da Silva o Ministério da Educação busca por profissionais ligados ao ensino para 
rever os PCNs. Nessa nova etapa o destaque foi para o Prof ${ }^{\circ}$ Amaury Cesar Moraes e sua equipe que redigiram as Orientações Curriculares Nacionais (OCNs), além de elaborar um Parecer:

[...] detalhado sobre a legislação educacional, desde a LDB de 1996 até as DCNEM (1998). Nesse Parecer consegue explicitar que as Diretrizes Curriculares Nacionais do Ensino Médio de 1998 não estavam cumprindo a LDB, pois não garantiam que os currículos oferecessem, de fato, os conhecimentos de Filosofia e Sociologia, apensa como temas transversais. (MORAES; GUIMARÃES, 2010, p. 30).

O Conselho Nacional de Educação analisa o Parecer e vota favorável às razões apontadas pelo Prof ${ }^{\circ}$ Amaury Cesar Moraes tornando obrigatórias a Sociologia e a Filosofia ao menos em uma série do Ensino Médio, fato que acarretou o questionamento de vários Estados da Federação quanto a decisão obrigatória que por sua vez resolveram aguardar o $\mathrm{CNE}$ antes de implementar as novas diretrizes, o que só ocorreu pela Resolução $n^{\circ} 1$, de 15 de maio de 2009, ordenando a implementação até o ano de 2011.

Da análise da trajetória da Sociologia para ser incluída como disciplina obrigatória, diriamos necessária, para o desenvolvimento e aprendizagem dos jovens, nos faz retornar as advertências do Prof ${ }^{\circ}$ Florestan Fernandes (1977, p. 98):

A posição do ensino secundário no sistema educacional brasileiro permite defini-lo sociológicamente, portanto, como um tipo de "educação estática", que visa unicamente a conservação da ordem social. [...] [assim] se estabelece uma vinculação muito forte entre a defesa da estabilidade do sistema educacional brasileiro e as concepções ou os interesses educacionais que orientam as intervenções políticas $\mathrm{e}$ administrativas de camadas conservadoras, socialmente poderosas e influentes. Eis o corolário dessa situação: um ensino médio sem possibilidade de tornar-se um "instrumento 
consciente de progresso social", isto é, incapaz de proporcionar uma "educação dinâmica". (grifos do autor).

E a advertência do Prof ${ }^{\circ}$ Florestan Fernandes, nos anos 1970, é de uma atualidade imprescindível àqueles que dedicam sua vida profissional ao ensino da Sociologia enquanto disciplina transformadora. Intervenções de natureza conservadora (podemos citar escola sem partido) e interesses travestidos de "pedagógicos", mas com objetivos e interesses lucrativos formam parte do pano de fundo contra o ensino da Sociologia atualmente no Brasil.

\section{O fomento de politica educacional perversa no Brasil.}

Citamos novo ataque pelo qual passa nossa disciplina atualmente em virtude da publicação da Lei $\mathrm{n}^{\circ} 13.415$, de 16 de fevereiro de 2017, ataque esse com dois pontos (existem outros) a serem analisados com cautela. O primeiro diz respeito à divisão do ensino em áreas de conhecimento:

Art. 35-A. A base Nacional Comum Curricular definirá direitos e objetivos de aprendizagem do ensino médio, conforme diretrizes do Conselho Nacional de Educação, nas seguintes áreas do conhecimento:

I - linguagem e suas tecnologias;

II - matemática e suas tecnologias;

III - ciências da natureza e suas tecnologias;

IV - ciências humanas e sociais aplicadas.

Essa divisão do conhecimento proposto, que por sua vez modificou parte da lei de Diretrizes e Bases da Educação brasileira de 1996, não contempla o ensino da Sociologia em nenhuma de suas divisões. No parágrafo segundo do mesmo artigo trinta e cinco, letra A, está claro a possibilidade do ensino de Sociologia ficar de fora dos currículos quando prescreve que a "[...] Base Nacional Curricular referente ao ensino médio incluirá obrigatoriamente estudos e práticas de educação física, arte, sociologia e filosofia." (BRASIL, 2017, grifo 
nosso). A despeito da menção "obrigatoriamente" constante do parágrafo citado, não significa que a Sociologia será uma disciplina de natureza obrigatória nos currículos, pois em matéria de lei há que se prestar muita atenção nos verbos, pois verbos indicam ação. Portanto, a palavra "incluirá" não se traduz, em linguagem jurídica, de que realmente a Sociologia será disciplina obrigatória, significa simplesmente que a Sociologia poderá (ou não) ser ministrada. O golpe perpetrado pela referida Lei é de um retrocesso perverso contra o ensino da Sociologia, pois corremos o risco de nem mesmo tê-la como forma de uma "educação estática" para relembrarmos as observações de Fernandes (1977).

A perversidade torna-se mais escandalosa quando identificamos os endereçados desta "reforma", além dos motivos que levaram a cabo a orquestração e publicação do instituto legal do golpe contra o ensino da Sociologia e suas consequências.

No primeiro caso recorremos ao texto Por que a urgência da reforma do ensino médio? Mota; Frigotto (2017) onde se encontram estipuladas as razões, de natureza ideológica para a efetivação da reforma do ensino médio no Brasil, demonstrando a estreita relação entre aprovação dos limites de gastos aprovados pela Proposta de Emenda Constitucional n 55 e o papel da "Escola sem partido". Mota; Frigotto (2017) lançam a pergunta do porque da urgência do ensino médio e encontram na necessidade de eliminar "barreiras que impedem o crescimento econômico" as razões oficiais da promulgação da Medida Provisória $\mathrm{n}^{\circ} 746 / 2016$, que continha as disposições legais da Lei 13.415/2017. "E a educação, principalmente a educação profissional, é um fator importante para a retomada do crescimento econômico, uma vez que o investimento em capital humano potencializa a produtividade." (MOTTA; FRIGOTTO, 2010, p. 357). Tal investimento em capital humano na intenção de aumentar (e melhorar) a produtividade, aliada a uma estrutura curricular que atendesse ao momento histórico da necessidade de trabalhadores treinados para o desempenho de determinadas tarefas, seria possível com a flexibilização de disciplinas 
eleitas para cada área do conhecimento, ou seja, a partir do momento em que o aluno escolhe sua área de estudos, as disciplinas guardarão estreita relação com sua atividade laboral, sem a necessidade de conhecer História, Filosofia e Sociologia. Vale reforçar nossa observação anterior de que a Lei 13.415/17 menciona o Português e a Matemática como obrigatórias e afirmando que as demais disciplinas como Educação Física, Arte, Sociologia e Filosofia serão obrigatoriamente "incluídas" nos estudos e práticas do ensino médio e nenhuma referência a Biologia e a Física.

Mas de boas intenções o inferno está repleto e Motta; Frigotto (2017, p. 359) desnaturalizam as argumentações das boas intenções.

A tese de "alcançar o pleno desenvolvimento" investindo em "capacidade tecnológica" e na força de trabalho com maior qualificação contradiz a longa história de baixo investimento na educação brasileira. (grifos dos autores).

Portanto, a falácia do investimento na educação para melhorar nosso desempenho produtivo não tem qualquer procedência. Quais razões de fato encontram-se na urgência da reforma do ensino médio? Necessário uma rápida análise histórica do contexto no qual estamos transitando, contexto este da nova configuração do capital a nível mundial iniciado nos anos 1980. Com isto também buscaremos argumentação para defendermos nossa ideia do golpe contra a Educação (e a Sociologia).

Foram os anos 1980 momento marcadamente acirrado da contraposição capital x trabalho anunciando a necessidade de enfrentar problemas e reorganizar a forma de reprodução dos mais variados seguimentos industriais na realização da mais valia tão necessária à reprodução do capital. Os sinais desta necessidade manifestaram-se no aumento do desemprego, que em certas categorias deu-se de forma estrutural, presença da informatização nas linhas de produção, a forte tendência de dessindicalização mundial e o avanço de uma economia cada vez mais integrada em âmbito mundial. 
Nesse contexto se dava a promulgação no Brasil, em outubro de 1988, de uma Constituição com forte viés social, que dentre outras importantes garantias, trazia em seu corpo uma sistematização dos direitos inerentes aos empregados e suas Entidades representativas; a universalização da Saúde; os princípios educacionais calcados em sua gratuidade e na gestão democrática, defendendo o pluralismo das ideias e a liberdade do aprender, ensinar, além da igualdade do acesso e permanência na escola.

Mas a conquista dos valores sociais cristalizados na Carta enfrentaria forte oposição em sua efetivação. Um conjunto de reformas elaboradas e colocadas em prática a partir de novembro de 1989 com receituário para países em dificuldades econômicas, para que retomassem seu desenvolvimento, elaborado nos Estados Unidos da América, impõe, dentre outras coisas, uma disciplina fiscal, a necessidade de privatizações, uma reforma tributária, abertura comercial, a desregulamentação da economia, principalmente no tocante às leis trabalhistas.

Era o denominado Consenso de Washington.

A adoção parcial do receituário do Consenso de Washington, no início dos anos 1990, sob o governo Fernando Collor de Mello (19901992), tiveram seus princípios "neoliberalizantes" aprofundados por Fernando Henrique Cardoso (1995-2003) na intenção clara de alinhar o Brasil ao neoliberalismo, declarando que seu governo era o fim da Era Vargas, ou seja, da intervenção do Estado na economia.

Desde então, sucessivos foram os ataques acusatórios com relação à legislação trabalhista, sobretudo contra a Constituição Federal de 1988 de maneira geral, pelos excessos protecionistas endereçados aos trabalhadores, dificultando e comprometendo, desta maneira, o desenvolvimento industrial e sua competitividade. Razão pela qual se buscou justificar e reforçar o argumento da necessária desregulamentação do mercado de trabalho brasileiro.

Trata-se da hegemonia do "imperialismo norte-americano". 
O PIB mundial está em torno de US\$ 25 trilhões. Apenas sete países, que formam o G-7, embolsam US\$ 18 trilhões. Estados Unidos, Canadá, Inglaterra, França, Itália, Alemanha e Japão. Sozinhos, os Estados Unidos possuem US\$ 10 trilhões. Isso significa que sobram apenas US\$ 7 trilhões para a sobrevivência das demais nações do mundo, que somam mais de 180. (BETTO, 2001, p. 7).

Para que esse montante de capital financeiro possa circular com mais segurança pelo mundo, os Estados Unidos modificam sua atuação com relação à política externa, sobretudo na América Latina, o que exigiu mudança de comportamento dos donos do poder no Brasil. Ao invés de invasão pura e simples (Panamá, Nicarágua), ou patrocínio de ditaduras (Chile, Brasil), entra em campo sua diplomacia. Não por acaso a Secretária de Estado Condoleezza Rice, durante o governo de George W. Bush (2005-2009) esteve em missão diplomática no Brasil com esse propósito: "discutir a estabilidade política e econômica na América Latina", além de colocar à disposição destes países o necessário "apoio dos Estados Unidos da América para garantir a prosperidade econômica da região." O recado chegara ao endereço correto: que os países abaixo do Rio Grande evitassem quarteladas e a utilização da força como atalho ao poder.

$\mathrm{O}$ avanço no sentido de flexibilizar assuntos ligados ao mundo do trabalho, educação, previdência e saúde foi reduzido com a chegada de Luis Inácio Lula da Silva ao poder. O presidente mais popular do Brasil lançou mão de uma política capaz de diminuir a pobreza e as desigualdades sociais por intermédio da distribuição de renda, seus programas sociais foram elogiados pelo mundo, isto tudo favorecido graças a um contexto econômico externo. Mas isso não significa que os donos do poder abriram mão da reforma do Estado no sentido de realizar e dar efetividade aos seus interesses. Aguardaram o momento para retomar os projetos neoliberalizantes atrelados aos seus propósitos. Foi com o denominado "mensalão" a oportunidade que tanto esperaram. 
E, mais uma vez, a tomada do poder no Brasil, em 31 de agosto de 2016, com a destituição da Presidente Dilma Rousseff, trouxe novidade na lógica da tomada do poder em nossa história: mais uma vez "pelo alto", mas sem quarteladas. Um golpe com apoio da classe média, insuflado pela mídia e aquiescência do Poder Judiciário. O golpe patrocinado contra a democracia brasileira nasce, mas não é seu desfecho, com as manifestações em protesto pelo aumento do transporte público na cidade de São Paulo em junho de 2013.

Com isto as políticas de caráter neoliberalizantes retornam com força ainda maior e num espaço de oito meses do governo de Michel Temer assistimos a uma escalada de investidas contra uma sociedade que busca justiça social: a definição de um teto para os gastos públicos aprovados em 13 de dezembro de 2016, o envio de reformas trabalhistas aprovadas pelo Congresso em 11 de julho de 2017, reforma previdenciária ainda em discussão, mas tudo indica que sua aprovação não se deu em virtude das proximidades das eleições de 2018 e a famigerada reforma do ensino médio publicada em 16 de fevereiro de 2017. As intenções dos anos 1980 se concretizaram e vem se concretizando a partir de 2016.

Com relação ao que nos interesse neste trabalho, a última reforma mencionada relacionada à Educação deixa evidente a perversidade contra a classe trabalhadora apesar das Diretrizes Curriculares Nacionais para o Ensino Médio - DCNEM afirmarem que as mudanças “[...] no currículo do Ensino Médio é de "interesse dos adolescentes e jovens, sujeitos desta etapa educacional." (MOTTA; FRIGOTTO, 2017, p. 362). Ao verificarmos quem são os "sujeitos" a tese da reforma contra trabalhadores ganha força. "Na rede privada foram 1.070.358 estudantes. Estavam matriculados no Ensino Médio regular nas redes estaduais urbanas e rurais 6.459 .859 alunos [...]" (MOTTA; FRIGOTTO, 2017, p. 362). A perversidade consiste na negação de ensino de qualidade e consequentemente do acesso ao ensino superior público para a maioria dos adolescentes, mas adolescentes oriundos das classes pobres. 
Analisar com mais cuidado a reforma do ensino médio, diante da nova configuração do capital a exigir, da Educação de forma geral, maior flexibilidade como faz Kuenzer (2017) só faz reforçar o que discutimos até agora.

O repúdio à maneira como a reforma foi introduzida na legislação brasileira é uma das primeiras críticas aventadas por Kuenzer (2017, p. 336) devido ao seu caráter autoritário:

[...] que orientou todo o processo, tudo em prazo exíguo, sem que fossem abertos espaços para o debate aprofundado pelos docentes, especialistas, pesquisadores e estudantes que atuam, estudam e sofrem a realidade do ensino médio no Brasil.

O caráter autoritário do processo no qual se refere a autora é a Medida Provisória. Criação do sistema legislativo italiano de Benito Mussolini, o regime brasileiro acabou importando o Instituto sob a denominação de Decreto-Lei, instrumento legislativo utilizado durante a ditadura civil-militar brasileira (1964-1985) que, na Constituição Federal de 1988, em virtude de seu desgaste, foi nominalmente repaginada como Medida Provisória. Mudou-se a denominação, mas conservou sua essência autoritária na maneira de legislar no Brasil.

Uma segunda critica dirigida pela autora recai sobre os itinerários, um total de cinco propostas, que seria inviável, menos ainda obrigatória sua oferta numa mesma escola; inviável em decorrência da falta de estrutura das escolas públicas brasileiras com a crônica falta de laboratórios, equipamentos, bibliotecas etc., o que sinaliza que a "[...] tendência será reduzir a oferta, privilegiando as áreas que dependem menos de docentes qualificados e de recursos materiais e tecnológicos [...]" (KUENZER, 2017, p. 336).

Uma última crítica a ser observada pela autora seria a redução "[...] da formação comum a, no máximo, 1.800 horas [...] e a escolha precoce [...] que o jovem ainda está se preparando para fazer suas escolhas." (KUENZER, 2017, p. 336). 
Diante deste contexto da flexibilização curricular há que se destacarem as implicações do que Kuenzer (2017) denomina de "aprendizagem flexível". No âmbito pedagógico procederá a uma aprendizagem "aligeirada" instrumentalizando o adolescente de habilidades direcionadas ao desempenho de determinada função laboral; da perspectiva metodológica é transformar o aluno em "sujeito de sua prática de aprendizagem" responsável por controlar suas próprias atividades de aprendizagem resultando num melhor aproveitamento de suas atividades acadêmicas, potencializado pelos recursos tecnológicos do ensino à distância.

Essa concepção metodológica desloca não só o professor, mas também o conteúdo para o grupo, mediante a organização de comunidades de aprendizagem, em que os alunos participam, envolvem-se, pesquisam, interagem, criam, com a mediação de algum orientador. A relação presencial passa a ser substituída pela tutoria, que acompanha a aprendizagem dos alunos. (KUENZER, 2017, p. 338).

Tais concepções pedagógicas e metodológicas estão em consonância com a Lei 13.145/2017 no sentido de favorecer grupos privados de educação, comprometidos não com a educação pública e de qualidade, mas com a possibilidade do capital avançar com sua sede de lucro, num filão que cada vez mais vem sendo explorado no Brasil, seja educação básica, bem como educação de nível superior.

Ai se encontra o fundamento dos ataques e investidas e do desmanche das Universidades Públicas brasileiras. O modus operandi é antigo: sataniza-se o objeto desejado pela iniciativa privada e convencer, sobretudo a classe média, aliada à classe dominante (aí entra o papel fundamental da mídia), da ineficiência das Instituições acabando por "vendê-las" ao "eficiente" mercado da iniciativa privada. Quem não se lembra da Vale do Rio Doce e Banco do Estado de São Paulo BANESPA, só pra citar dois exemplos dos governos Fernando Collor e Fernando Henrique Cardoso. 
Agora todo os esforços privatizantes são dirigidos ao ensino de forma geral: fundamental, básico e superior. Atenção a uma holding denominada Saber, subsidiária da uma empresa conhecida como Kroton, que tem como presidente Rodrigo Galindo, realizando negócios de bilhões de reais na transação no âmbito da educação superior e básica.

Atualmente a Kroton, na intenção “[...] de aumentar sua participação no mercado de pós-graduação [...]" (OLIVEIRA, 2018, p. A21) buscou parceira com a Udacity (empresa de startup do Vale do Silício) e "lançaram juntas" um curso de MBA.

Com 1 milhão de alunos no ensino superior, área responsável por $97 \%$ do faturamento da companhia, a Kroton tem 40 mil alunos na educação continuada. Rodrigo Galindo, presidente da Kroton, diz que ela tem potencial de crescer de 4 a 5 vezes nesse mercado. (OLIVEIRA, 2018, p. A21, grifos nossos).

É a efetivação dos projetos dominantes gestados no contexto sócio-político-econômico dos anos 1980.

A conclusão clara é que a contrarreforma do Ensino Médio por imposição autoritária de Medida Provisória é congruente e necessária para sustentar violência da PEC 55, que expressa o desmanche dos direitos universais da classe trabalhadora mediante o congelamento dos recursos públicos para a educação, saúde, cultura, etc. (MOTTA; FRIGOTTO, 2017, p. 368).

Sintese do atual panorama contido nas palavras dos autores: diante da opção política no sentido de salvaguardar interesses de rentistas, pois a Proposta de Emenda a Constituição - PEC 55 destinada ao limite de gastos por parte do poder público nada mais é do que isto em sua essência, atrelada a uma legislação trabalhista flexivel onde a realização da mais valia não encontrará barreiras nem 
contestações, permitindo a privatização generalizada, em particular, da Educação com único objetivo da realização do lucro em detrimento da formação humana são os componentes do novo horizonte político.

\section{Considerações finais}

Ao abordarmos a intermitência do ensino de Sociologia nas escolas brasileiras foi possivel percebermos que uma "nova proposta educacional" está em marcha no Brasil. Esta "nova proposta educacional" parece desabrochar neste momento onde são adotadas práticas políticas-econômicas em nome do desenvolvimento e bem estar humano.

$\mathrm{Na}$ verdade a elite brasileira após 2016 tomou pra si garantir as estruturas necessárias à integridade e funcionamento de um regime econômico que levará o Brasil, em particular nossa Educação à barbárie.

Barbárie de natureza educacional com o aumento da evasão escolar; impedindo uma formação voltada para a emancipação; "formando" sujeitos incapazes de compreender o mundo ao seu redor; bloqueando o acesso ao conhecimento para grande parte dos jovens brasileiros; precarizando ainda mais o trabalho docente, consequentemente uma maior desvalorização do profissional da educação; sem investir na recuperação, manutenção e melhoria das estruturas de nossas escolas; comprometendo o desenvolvimento da pesquisa e extensão entregando nas mãos dos mercenários da educação vultuosa verba orçamentária destinada à Educação brasileira.

Combater mais este bárbaro projeto educacional é função primordial, caso contrário o trabalho docente no futuro consistirá num esforço hercúleo de "desbarbarização" (ADORNO, 2003) dos estudantes brasileiros.

\section{Referências}


ADORNO, Theodor W. Educação e emancipação. Trad. Wolfgang Leo Maar. São Paulo: Paz e Terra, 2003.

BETTO, Frei. O sonho traduzido em realidade. Prefácio. In: MAURO, Gilmar; PERICÁS, Luiz Bernardo. Capitalismo e luta política no Brasil na virada do milênio. São Paulo: Xamã, 2001.

BRASIL, Lei $\mathrm{n}^{\circ} 13.415$, de 16 de fevereiro de 2017. Altera as leis $\mathrm{n}^{\circ} \mathrm{s}$ 9.394, de 20 de dezembro de 1996, que estabelece as diretrizes e bases da educação nacional, e 11.494, de 20 de junho 2007, que regulamenta o Fundo de Manutenção e Desenvolvimento da Educação Básica e de Valorização dos Profissionais da Educação, a Consolidação das Leis do Trabalho - CLT, aprovada pelo Decreto-Lei $\mathrm{n}^{\circ} 5.452$, de $1^{\circ}$ de maio de 1943, e o Decreto-Lei $n^{\circ} 236$, de 28 de fevereiro de 1967; revoga a Lei $n^{\circ}$ 11.161 , de 5 de agosto de 2005; e institui a Política de Fomento à Implementação de Escolas de Ensino Médio em Tempo Integral. Câmara dos Deputados, Brasília, DF. Disponivel em:

http://www2.camara.leg.br/legin/fed/lei/2017/lei-13415-16-fevereiro2017-784336-publicacaooriginal-152003-pl.html Acesso em: 27 jun. 2017.

FERNANDES, Florestan. O ensino de sociologia na escola secundária. A sociologia no Brasil. Petrópolis, RJ: Vozes, 1977. Disponível em http://www.sbsociologia.com.br/portal/index.php?option=com_docman \&task $=$ cat_view\&gid $=164 \&$ Itemid $=171$

KUENZER, Acácia Zeneida. Trabalho e escola: a flexibilização do ensino médio no contexto do regime de acumulação flexível. Revista Educ. Soc. Campinas, v. 38, n 139, p. 331-354, abr. jun., 2017.

Disponivel em http://www.scielo.br/pdf/es/v38n139/1678-4626-es38-139-00331.pdf

MARX, Karl. O 18 Brumário de Luís Bonaparte. In: Manuscritos econômicos e outros textos escolhidos. Tradução José Carlos Bruni (et al.). 2 ed. São Paulo: Abril Cultural, 1978. p. 323 - 404. (Coleção os pensadores)

MORAES, Amaury César. GUIMARÃES, Elisabeth Fonseca da. Metodologia de ensino de Ciências Sociais: relendo as OCEN-Sociologia. In: MORAES, Amaury César (Cood.). Sociologia: ensino médio. Brasília: Ministério da Educação, Secretaria de Educação Básica, 2010. (Coleção Explorando o Ensino, v. 15).

MOTTA, Vânia Cardoso da; FRIGOTTO, Gaudêncio. Por que a urgência da reforma do ensino médio? Medida Provisória $n^{\circ} 746 / 2016$ (Lei $n^{\circ}$ 13.415/2017). Revista Educ. Soc. Campinas, v. 38, no 139, p. 355-372, abr. jun., 2017. 
Disponivel em http://www.scielo.br/pdf/es/v38n139/1678-4626-es38-139-00355.pdf

OLIVEIRA, Filipe. Kroton e startup do Vale do Silício lançam MBA em marketing digital. Folha de S. Paulo, São Paulo, 28 jul. 2018, Mercado, p. A21.

SILVA, Ileizi Luciana Fiorelli; SANTOS, Mário Bispo. O ensino das Ciências Sociais/Sociologia no Brasil: histórico e perspectivas. In: MORAES, Amaury César. (Cood.). Sociologia: ensino médio. Brasília: Ministério da Educação, Secretaria de Educação Básica, 2010. (Coleção Explorando o Ensino, v. 15). 